\title{
Building A Health Administration Program: Strategies For Success
}

\author{
Kathleen H. Galbraith, (E-mail: Kgalbraith@ubalt.edu), University of Baltimore \\ Margaret Gillingham, (E-mail: Mgillingham@ubalt.edu), University of Baltimore \\ Manuel Dieguez, (E-mail: Manuel.Dieguez@ fiu.edu), Florida International University \\ Rosalie Hallbauer, (E-mail: Rosalie.Hallbauer@ fiu.edu), Florida International University \\ Dana A. Forgione, (E-mail: Forgione@ fiu.edu), Florida International University \\ John A. Wrieden, (E-mail: John.Wrieden@ fiu.edu), Florida International University
}

\begin{abstract}
Nearly 200 students have now graduated from the University of Baltimore's (UB's) six-year-old undergraduate Health Systems Management program (HSMG). With a total student enrollment of 113, the program is one of the larger health administration programs in the United States. The program, an affiliate member of the Association of University Programs in Health Administration, is a unique weekend program that allows working professionals with an Associate's degree to complete a Bachelor of Science degree in 21/2 years. The students have, on average, 10-15 years of experience in the heath industry either as nurses or radiology technicians, thus bringing extensive practical experience to the classroom. By any academic measure, the program has been a success. Recruitment is strong and steady, the retention rate and graduation rate (over 80 percent) is high compared to both the university and national averages, and over 90 percent of the graduating students finish in the 21/2 years.
\end{abstract}

The purpose of this paper is to discuss the issues and strategies involved in implementing the program, as well as some of the unique features of this program. We believe our success can be replicated in other university and program settings. The health care employment market in the greater Baltimore region provided a significant student population base from which we were able to draw for enrollment in our HSMG program. Other regional markets can be addressed in a similar fashion to meet the educational needs of students and enhance the achievement of university enrollment goals.

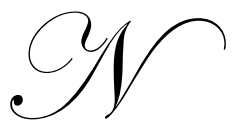

early 200 students have now graduated from the University of Baltimore's (UB's) six-year-old undergraduate Health Systems Management program (HSMG). With a total student enrollment of 113 , the program is one of the larger health administration programs in the United States. The program, an affiliate member of the Association of University Programs in Health Administration (AUPHA), is a unique weekend program that allows working professionals with an Associate's degree to complete a Bachelor of Science degree in $2 \frac{1}{2}$ years. UB is an upper division school, accepting only students who already have an Associate's degree, or 60 credits. The students have, on average, 10-15 years of experience in the heath industry either as nurses or radiology technicians, thus bringing extensive practical experience to the classroom. By any academic measure, the program has been a success. Recruitment is strong and steady, the retention rate and graduation rate (over 80 percent) is high compared to both the university and national averages, and over 90 percent of the graduating students finish in the $2 \frac{1}{2}$ years. A Masters program in Health Systems Management was also started four years ago along with an accelerated Bachelors-Masters program for Honors Students in the HSMG program. The purpose of this paper is to discuss the issues and strategies involved in implementing the program, as well as some of the unique features of this program.

UB was originally founded as a private college in 1925 by a group of Baltimore civic leaders who wanted to provide inexpensive part-time and evening studies for working adults. It is now a State University and part of the University System of Maryland. The University System of Maryland is now the $12^{\text {th }}$ largest educational system in the 
nation and consists of 13 institutions. UB is one of the smaller of these institutions with an undergraduate program that has a student population of less than 2,000. Total University Enrollment is now listed as 4,655. It is an upperdivision school, enrolling only students who have completed 60 credits or an Associate's degree. As part of the State system, the University has a number of articulation agreements with community colleges to facilitate transfer students with Associate's degrees. It has a reputation as the in-state school for working professionals. This program, and a number of other new initiatives, reversed the decline in enrollment — a trend that began prior to 1998.

\section{HEALTH IS TRULY A PUBLIC AFFAIR}

Where do undergraduate health programs belong? In reviewing the AUPHA 2003-2005 directory there are 42 AUPHA accredited programs, of which five (12 percent) are in Schools of Business, two are in Schools of Urban Affairs / Political Science (5 percent) and the remainder are under Health-related departments (83 percent). (Reed, 2003).

Traditionally at UB, the department that initiates a program, also develops and implements the proposal, and that department becomes the "home" at least for the first several years. At UB, several different schools had health concentrations of three courses at the graduate level, including the public administration programs, the business program, the psychology program, the human services program, but none offered either an undergraduate or graduate degree in Health Management.

In this case, the Health Systems Management proposal was sponsored by the School of Public Affairs at UB. This seemed a suitable placement because in the State of Maryland, where all but one of the hospitals are non-profit and subject to public rate-setting, an argument could be made that "Health is truly a public affair." Certainly, this became our theme after we started the first class and helped to finalize the curriculum and implement the program. The School of Public Affairs with both an undergraduate government program and a graduate public administration program had a strong and savvy faculty group, and turned out to be an excellent home for the start of this program. This organizational structure at UB is depicted in Exhibit 1.

Exhibit 1: UB Organization

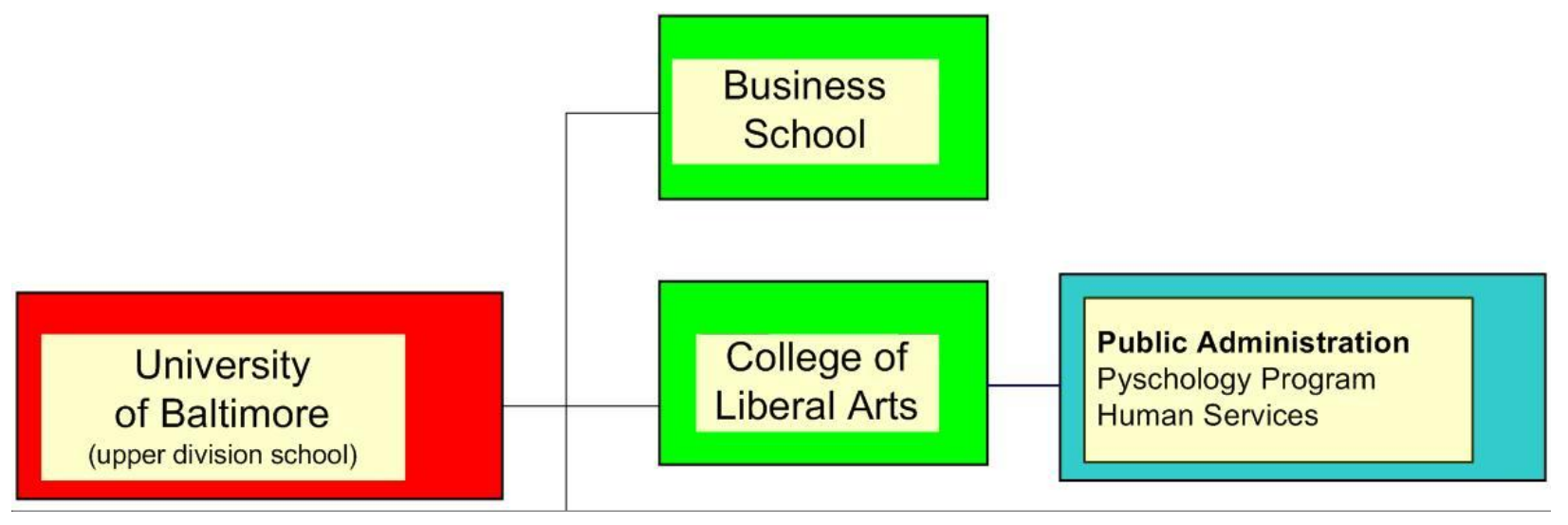

The undergraduate program, Government and Public Policy (GVPP) in the School of Public Affairs agreed to act as an umbrella for the new HSMG program. As is typical again at UB, the program was started under the auspices of this program, and the first students were matriculated as GVPP students until formal approval of the new HSMG program could be completed. Fortunately, the GVPP program had room for a number of electives. This arrangement allowed the students to be admitted immediately as GVPP students, and the electives were used for the newly developed HSMG courses. If, at this point, the approval had failed, students would not have lost any time, would still be given credit for their courses, and still would be able to receive a Bachelor of Arts in GVPP with a concentration in 
Health Management. This strategy allowed us time to more formally develop the program and the curriculum, while allowing the University an opportunity to assess the potential student market. This format presented minimal risk to the students. No course was offered during this initial period that could not be transferred to another degree program at the University.

This strategy does work and helps minimize start-up costs and risk for new programs. At the time of the program start-up, UB was undergoing some challenges in terms of student enrollment. Undergraduate enrollments had been declining steadily for several years. Consultants had advised the University to consider new programs and new satellite offerings to improve the enrollments. Therefore the atmosphere was favorable to starting the programs, but the financial support was not. A common joke was that "if you build it and it works, then we will support it," or the "sweat equity" approach.

It was somewhat risky building a program with limited resources, but with the rapid growth of the program from 18 to 125 students in two years, it became obvious that the program would be able to sustain itself. So when the Graduate HSMG program was started three years after the undergraduate program, the same approach was used, starting it under the auspices of the Master of Public Administration Program, which had a health concentration of three health administration courses. Like the undergraduate program, until the internal and external review process for the proposal was completed, no courses were offered unless they could be applied to both programs, again minimizing risk to the students and also to the University.

Part of our charge was to immediately finalize a formal proposal to go through the various college committees and since the University was part of the State system, to also be approved by the Maryland Higher Education Council. The internal process consisted first of developing a proposal and designing the curriculum. In the next step, the department and then a small faculty curriculum group approved the proposal. The curriculum committee basically reviewed the proposal for its soundness. It was then submitted to the Program Directors in the College. This is an important group because it is where the "public buy-in" for the program by other academic departments takes place. Obviously, since any undergraduate program is going to require course offerings from other departments, that public vote of confidence is essential. The proposal next went to the Provost's Council and then finally outside the university to the Maryland Council of Higher Education. The entire process took almost six months. But by the time we received official approval, we had approximately 30 students with 12-24 credits ready to transfer into the newly approved HSMG program.

\section{IF YOU BUILD IT, WILL THEY COME, AND WILL THEY KEEP COMING?}

The health sector is the second largest industry group in Maryland at 193,150 employees with approximately 10,000 employed in Executive, Administrative or Managerial occupations (Arnold, 2000). The Office of Labor Market Analysis and Information of the Maryland Department of Labor, Licensing and Regulation projects health occupations in Maryland to account for 37,000 additional jobs by 2006, or one in nine new jobs in Maryland (Arnold, 2000). The Maryland Department of Labor, Licensing and Regulation cited "the importance of the health services industry to Maryland's economy and the excellent employment opportunities it will generate" (Arnold, 2000). By 2006, 20.6 percent of the professional and technical workers in Maryland will be in health care, emphasizing the significance of providing a trained workforce with advanced education in health systems management in sufficient numbers to support this growth.

The US Department of Labor, Bureau of Labor Statistics (2003) states that employment of health service managers is expected to grow faster than average for all occupations through 2008 as health services continue to expand and diversify. Hospitals will continue to employ the most managers, although the number of jobs will grow more slowly compared to other areas. As hospitals continue to consolidate, centralize and diversify functions, competition will grow at all job levels. Employment will grow the fastest in home health agencies, residential care facilities and practitioner's offices and clinics. Many services previously provided in hospitals will be shifted to these sectors, especially as medical technologies improve. Demand in medical group practice management will grow as medical group's practices become larger and more complex. Health service managers will need to deal with the 
pressures of cost containment and financial accountability, as well as the increased focus on preventive care, and will become more involved in trying to improve the health of their community.

\section{WHAT'S THE COMPETITION? WHO CAME?}

In the State of Maryland, we found a number of undergraduate programs with health management concentrations, but only a few were offering a Bachelor degree in Health Administration. The two undergraduate programs, both within the University of Maryland system, were offering four-year programs to traditional full-time undergraduate students. Since UB is an upper-division program, we focused on the adult learner with several years of work experience. We found that there were many students who had advanced as far as they could without a Bachelor's degree. Furthermore the majority had 10-15 years of experience in a health service setting and they were anxious "to take their turn at the helm." Many already had management positions but no formal management education. The first class was emphatic in telling us that: (1) they needed a program where they did not have to quit their current job, (2) they felt they were "too old" for traditional programs and (3) they needed the degree "yesterday."

Over 90 percent of our students worked full-time and carried a full-time load of 12 or more credits in our program. The 10-week terms comprising the semester with only two courses at a time greatly facilitated this. Our student population was made up of largely nurses, respiratory therapists (RTs) and some other health services positions. An analysis of our 200 graduates shows that 22 percent were nurses, 22 percent were RTs, 10 percent worked in the clinical fields and the remainder worked chiefly in other aspects, such as billing, but primarily in a health care setting. One would have thought schools of nursing to be a competitor. But the nurses that came to us were very insistent that they did not want to get a Bachelor's degree in Nursing, but instead were interested in obtaining more general health management skills. Given the age of the nurses attracted by the program, this was not surprising. These nurses had already spent 20 years "on their feet" and, like other professionals, were ready to take their turn "at the helm." Another interesting thing about nurses and RTs is that the combination of a professional clinical license and several years of clinical experience was a good predictor of student success, regardless of their prior grade point average (GPA). Thus far, the majority of nurses and RTs have graduated with honors.

The average age of our students in general was slightly higher than that of the general student population at the university. We had many students in the age range of 40-55 years. About 37 percent of our student population was African-American, and 4 percent were international students.

\section{WHAT MADE THE PROGRAM WORK?}

Putting the customer first is perhaps the most important strategy for any program director. UB had a number of factors that enabled us to do this. The initial cost was priced appropriately at $\$ 4,200$ a year. In addition, the University had a generous merit scholarship program. A Dean's scholarship of 50 percent was available for nearly all qualified students with a previous cross-institutional GPA of 3.25 or better. This was an attractive feature and helped in the recruitment and retention of qualified candidates. We also had a generous amount of available financial aid since the students were full-time students. Finally, because we were targeting working health professionals, many of the students were receiving \$2,000 a year in benefits from their workplace to attend school. Once students have the finances resolved, they can be more attentive to their studies.

The curriculum was strong and immediately relevant to the working student. Since we were an upper divisional school, taking mainly students who had completed their Associate's degree, we could immediately introduce the student to the HSMG courses, rather than focusing largely on the general education requirements.

The program had two advantages in terms of curriculum development. The first was that the curriculum was developed using AUPHA guidelines. The second was that UB is well known for its outstanding education in administration. Its Public Administration program is nationally ranked, and the Business Administration program had also received national recognition. Nearly every administration program requires courses in ethics, law, statistics, policy, research methods and program evaluation, organization behavior and design, financing, budgeting and/or economics, strategic management and, indeed, these were the broad categories used by AUPHA. Decisions were made 
regarding which courses were to be used from other departments and which we thought truly needed to be offered in a health care format by our own program and with our own HSMG code. Needless to say, the approval process goes faster when courses from other departments can be used.

It goes without saying that the faculty members were caring and extremely competent, with experience in the health field, policy analysis and college teaching. Many of the courses were taught by Adjunct faculty. We looked for Adjuncts who had some experience in working with students and were more collegial than autocratic in their interactions with students in our adult education setting. The Adjuncts we hired were usually health industry experts, and in addition to being extremely competent, they were genuinely collegial people who liked students and liked teaching. The faculty had a genuine interest in the career advancement of the students. Quality of the students' work was emphasized and faculty members were encouraged to be flexible when possible with deadlines. We were unwilling to compromise on the quality of the students work, but we could certainly be flexible with assignment deadlines as appropriate.

Two major features that contributed to the success of this program were (1) the cohort formats and (2) the scheduling formats. Both of these are extremely beneficial to the adult learner. Each semester of the program was made up of two 10-week terms. With this arrangement, students could be considered full-time students and, thus, were eligible for full-time tuition rates, scholarships, and financial aid. Yet, students carried only two 3-credit courses at a time, with one meeting Saturday morning and the other in the afternoon. This feature of carrying only two courses at a time is important with adult learners, and we believe that it is one of the reasons for our high rate of success. Many students have reported "having only two courses at a time, all day Saturday for 10 week sessions is what makes this program manageable. Anyone can do anything for only 10 weeks at a time." "Without this flexible scheduling, it would be impossible for most of us to go back to school." "Many of us are in our 40s and 50s." "We need to be able to keep our full-time jobs and yet many of us needed a Master's degree yesterday and we don't have the luxury of time to complete these programs and make them count."

The initial design of the program was that of a cohort program. While we do not strictly adhere to this structure, for the most part students do go through as a group. Cohort programs have a number of advantages such as:

1. Enabling us to organize a highly structured program, offering only those classes that are needed and ensuring that there are a sufficient number of students. This helps in making the program more cost-effective to the University.

2. $\quad$ Enabling us to ensure students that the schedule will always provide the needed classes.

3. Enabling us to provide a strong integrated program that builds one course on another. Sequencing in such a program can help significantly to strengthen the curriculum. It also ensures that all learners generally come prepared with the same course background.

4. Cohorts give the members "a sense of belonging" and acceptance "for their expertise and contributions." "...cohort students tend to persist in their studies, demonstrating increased commitment and motivation." (Barnett, et al., 2000)

5. Clearly expressed purposes of the cohort structure have been shown to lead to a "greater probability of success." (Barnett, et al., 2000)

6. The literature in adult learning indicates that adults learn best when they can direct their own learning, influence decision making, focus on problems relevant to practice, tap their rich experiential background, and build strong relationships with peers." (Barnett, et al., 2000)

7. Some evidence has shown "that the cohort experience can influence students' professional relationships and practices," especially maintaining professional contact with members of the group. (Barnett, et al., p. 259)

The disadvantages of a cohort program include:

1. Lock step nature

2. $\quad$ Lack of course flexibility

3. Lack of diversity in fellow-students (same colleagues for $2 \frac{1}{2}$ years), this can result in personal conflicts between the students. 
4. Faculty may not like the approach because the students are more demanding of their time and tend to challenge the relevance of the course content

5. If faculty members teaching in the program are paid differently from those who do not, it can create tensions between colleagues.

6. “...faculty do not always sense that cohort students are well served, noting problems with increased time demands on students, grade inflation, a few students dominating the group, and a 'watering down' of the curriculum because they are exposed to less theory. (Barnett, et al., 2000)

By using a cohort approach, we were able to develop a notable and cohesive academic community for the HSMG program. A typical disadvantage of a non-traditional weekend program is that students do not feel they belong to either the University or to the Program. To mitigate the potential disadvantages and encourage cohesiveness, we developed a student "buddy" program where senior students paired with a new student. Ties within the HSMG academic community were made stronger by the use of the electronic classroom program, PROMETHEUS. All classes taught in the HSMG program were given a PROMETHEUS forum. All faculty members were requested to electronically post their syllabus and handouts whether or not they planned to use them throughout the term. Use of these classroom forums greatly enhances communication and cuts down substantially on the need for photocopies. It is also good for last minute announcements. The Web Administrator generously set up an HSMG student exchange PROMETHEUS site that included all HSMG students. The forum contains the email of all HSMG students and faculty teaching in the Saturday classes in the HSMG program. Students could send broadcast emails to other students interested in selling books, announcing events, etc. A frequent use of the HSMG Student Exchange is by students posting jobs available at their work sites. The Web Administrator has since given us a site for the HSMG Graduate Student Union, Upsilon Phi Delta, and for an HSMG Alumni Society.

With the Student Affairs office, we were able to develop a series of activities specifically for the HSMG student body. These included a welcome-back luncheon at the start of each semester, an honors recognition ceremony, again at a noon luncheon, for all students, who had made the Dean's list, won a scholarship or earned any other recognition. Since all students were available at the same time at lunch on Saturday, we would try to have the Student Affairs Office arrange student events at this time. On weekdays, there were a number of events such as pancake breakfasts, pizza affairs, and Opening Day party. But the HSMG students worked full time and were unable to take advantage of this use of their student fees. Since all students were free at the same time at lunch on Saturday, we would try to have the Student Affairs Office arrange student events at this time, reminding them that students also needed to eat lunch since they had an afternoon class. The HSMG student association would also help sponsor some noontime activities including potluck luncheons welcome back lunch and a mentor-buddy lunch.

\section{RUNNING AGAINST THE WIND}

Starting a new program in a traditional setting can be a daunting task. If Machiavelli were writing advice for new college programs, surely he would advise that "new programs should be successful but not too successful." New program managers should be humble and attempt to keep a low profile. New programs should not overshadow other programs and new programs should not "cannibalize" their fellow programs, or inconvenience faculty of other programs. New programs should pay special attention to outcomes and accountability and especially to the financial bottom line. Getting through internal politics at a college can be difficult; someone compared it to running a football down the field, only to find your own team members are trying to tackle you.

Typical problems that are encountered in developing new programs:

1. Politics: Is your new program going to compete with our old program? Does your department have good relations with our department?

2. Resources: Office space and faculty; Funding. Is the program going to sustain itself

3. Students : Fear of "cannibalizing other programs" for students

4. Marketing: Advertising is expensive. In general with highly professional clinical staff a three-pronged approach is needed: the student reads about the program in a professional publication, they see it advertised 
in their work place and may receive a brochure in the mail, and finally they hear about it from their colleagues.

5. Support Services: Admissions, financial aid, student affairs: A traditional university is not set up for special cohort, week-end or accelerated programs and there is usually resistance to changing procedures to make accommodations, even when it would seem as if it was in their own best interest to do so.

\section{PAYING ATTENTION TO OUTCOMES}

Economists will say that the key to success is accountability. Educators will say that highly motivated students and a highly structured program is the best of all worlds for college programs. It is important to be vigilant regarding the curriculum and student satisfaction. It is also important to pay attention to the numbers: determine if your program is financially self-sustaining, or an economic burden to the school. All programs have a break-even point and most are heavily dependent upon student enrollment. Some may object to the heavy emphasis on numbers arguing that this detracts from the quality and excellence of the program. Yet, the sooner the program grows, the stronger the argument for additional resources and the lower advertising costs will be, since the program will advertise itself through students.

Actually, the enrollment numbers are a good proxy of a school's external reputation, and retention numbers are an excellent proxy of the internal quality of the program. Other outcome measures of importance are student salaries or promotions, numbers of graduates that attend graduate school, and average length of time that it takes for graduates to complete the program.

In our last survey, our graduates report salaries in the $\$ 40,000-\$ 105,000$ range. Interestingly, about 25 percent of the students reported a salary increase or a job promotion within the first six months of starting the program, something we can possibly attribute to a "Hawthorne effect." At this time, about 20 percent of graduates have gone on to a master's degree program. Both the retention rate and graduation rate is high, and even more rewarding is the knowledge that 95 percent of our graduates completed the program in $2^{1 / 2}$ years. This is extremely gratifying in that many of these same students took 5-7 years to complete an Associate's Degree.

\section{ADVERTISING A NEW PROGRAM-GOING PUBLIC}

With respect to advertising and a few very specific strategies, it should be noted that UB had no prior health program. The public relations department was just as new to advertising in the health field as we were. Marketing to health care professionals is a unique niche, so we ended up playing a much larger role in shaping the direction of our marketing efforts than might otherwise have been the case. Since we were trying to attract the working health professional, the most obvious source of advertising (community college guidance counselors) for an upper division school was not enough. The community college was the usual source of students for other UB programs, but we had very few students who came directly to the Health Systems Management program after completing their Associate's degrees. Consequently, the advertising was aimed at places where we would find health professionals: Hospitals, State Government Department of Health and Mental Hygiene, the Centers for Medicare and Medicaid Services (CMS, formerly HCFA), which is headquartered in Baltimore, BlueCross-BlueShield Care-First and other large insurance companies, and managed care firms. We did this through announcements, emails, and paid ads, mailings and brochure distribution. Our promotional model is presented in Exhibit 2. 
Exhibit 2: Promotional Model

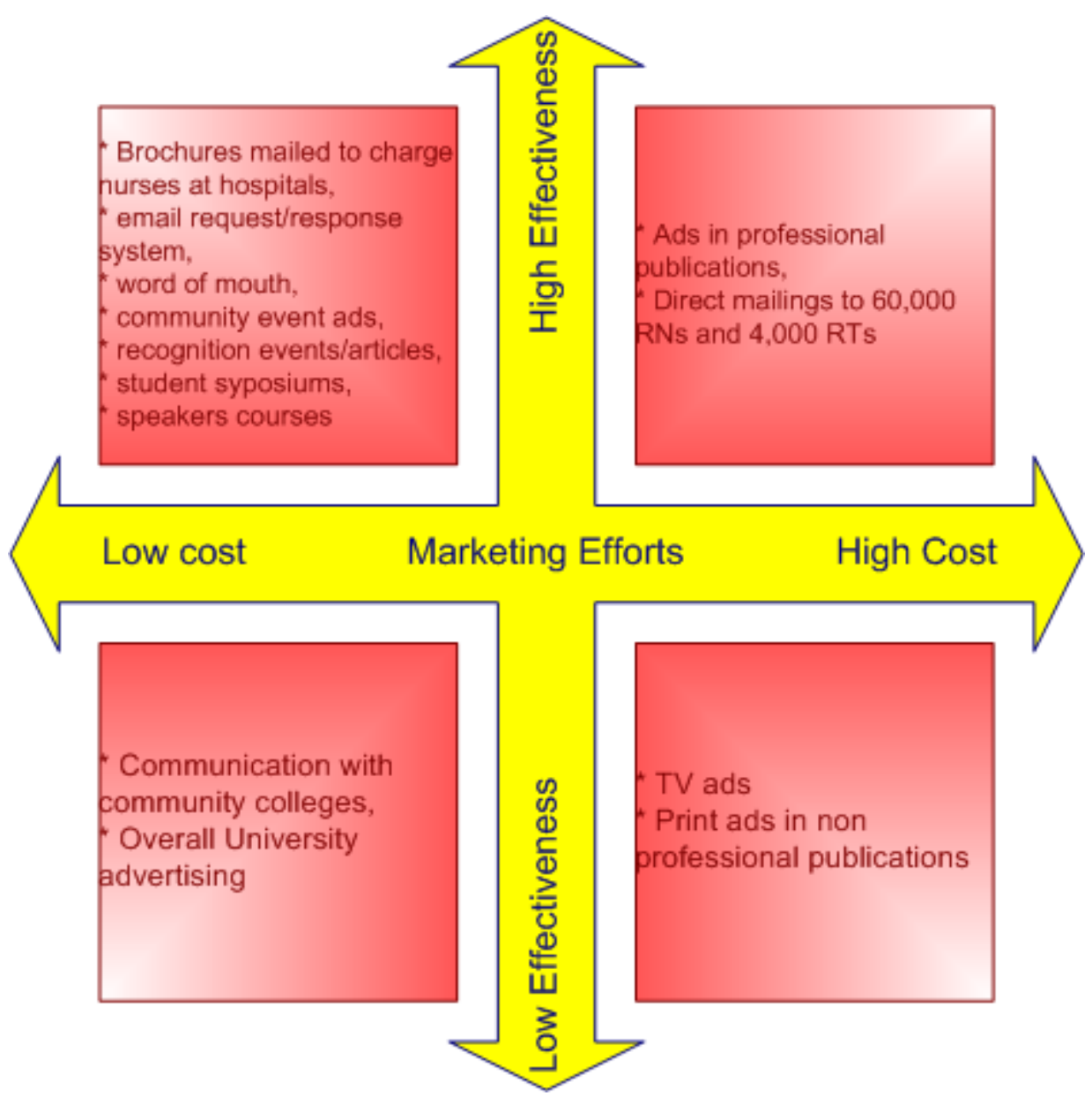

\section{PAID ADS}

Advertisements were placed in the Nursing Spectrum; The Maryland Nurses Association with a distribution of over 60,000 Maryland nurses, and the RT Scanner with over 5,000 RTs. Approximately 35,000 of the nurses had an Associate's degree, although we could not determine which ones. Hence, we mailed to all of them with hopes that they might pass on the information to a colleague. We put a section in the brochure, describing the Masters of Public Administration Program with the health concentration, to appeal to nurses who already had their bachelor's degree. Advertisements in professional journals are expensive, often costing upward to $\$ 1,000$ per ad. Yet, it is important to advertise in well-known professional journals in order to achieve some credibility and we considered it part of our three-pronged approach.

At the time of the conception of our program, The UB Public Relation's department was taking a new tack in addressing enrollment issues, and at the recommendation of a consultant it focused its efforts on UB as a whole. The program directors, however, reasoned that prospects choose a city university because of the program, and UB had many excellent and unique programs. We wanted marketing efforts to focus more on programs. But the commitment of advertising funds had been made, and as a result program directors were left to their own devices to advertise their program, yet, provided there was minimal approval, they were also given more of a free rein to be creative and implement their strategies. 


\section{EVENT PUBLICITY-FREE ADS}

Confronted with budget realities, we started searching for other ways to advertise. One way was the publicity that comes from sponsoring and advertising program events. As part of a management assignment, students arranged symposia open to both students and the larger health services industry. This included arranging for speakers, advertising and hosting the events. Students came up with the idea of offering contact hours (as opposed to Continuing Education Units) for the event, and developed a certificate. Hospitals, always interested in continuing education, were helpful in advertising these, often via their email systems. While attendance was never over $80-100$ people, the advertisement went many places.

For the Health Policy and Politics class, we used a format where we have a large group meet for public speakers and then return to the classroom for smaller group discussion. The speaker's series was one of the students' favorites. We decided to open the Speaker series part of the Health Policy and Politics Class to the general public. In this case, only a handful of people attended from outside (10:30 a.m. on Saturday is not a great sell-out time), yet we were still able to generate some publicity and public goodwill.

Another advertising strategy was "Home Page" news. Since the HSMG program was on a different schedule from the much of the University, the HSMG program had an Honors Recognition Ceremony to honor all students who had made the Deans List, High Honors, and/or received a Merit Scholarship every semester. This was held at a noon luncheon between classes for all HSMG students. We hired a photographer several times and took many pictures as each student received his or her certificate. We had hoped to have the Public Relations Department write a Home Page News article and send it with a photograph to the student's hometown newspaper and work site. This approach takes a great deal of effort but does save on advertising costs. It is said that a picture is worth a thousand words, and indeed it is in advertising. It brings good publicity to the school and to the program. On another tack, we were surprised at how popular these ceremonies were and how important this recognition became to our highly competitive students. It was a good way to emphasize the importance of academic excellence for the program.

\section{Web Site}

Every program needs an Internet web site. Programs were generally left on their own to design and post their specific program information. Fortunately, there was a computer class offered on web site design at UB, and the faculty member sent out an email message requesting web site projects for his students. As a result we had a web site linked to the University's web site that described our program. We included an "email intake form" so that visitors to our site could request program information. This form went directly to the program director and then was forwarded to admissions. Hence the program director could immediately call or email the prospective student and start a dialog. A personal touch and a genuine interest in the student's career advancement facilitate successful recruitment.

\section{Mailings}

A disk with mailing labels for all nurses in Maryland was bought from the State Board of Nursing and a selective county mailing was done. A list of all hospitals in Maryland was used and a mailing of our brochure done to the Director of Nursing, The Director of Human Resources, The Director of X-Ray services and the Director of Public Relations. We found that it was most important to get the brochure to the prospective student, and that even sending multiple brochures to key offices in the hospitals did not assure the employee would get them. Another strategy was to obtain the name of various units at the major hospital and send the brochure to e.g. "Charge Nurse, Nursing Station 2 South." These mailings were most likely to be posted on the nurses' bulletin boards. Brochures were given to students who wished to give them to their colleagues. Many students took brochures to put on the bulletin boards in the various nursing stations, and in their work site.

\section{Emails}

Spam was out of the question but yet so many students requested information that we formatted a copy of our brochure for email distribution and forwarded it to students with encouragement to "Change a colleague's life — send 
them to college." We would thank students profusely for referrals; always emphasizing that a referral to our program was the highest compliment that they could pay their alma mater. Nearly all hospital email systems had systems with firewalls, and many had regulations regarding the circulation of email advertisements. Some flatly refused to circulate any announcements to their staff stating that they considered it vendor advertising. Still many hospitals were happy to circulate email notices of Open Houses and Merit Scholarship announcements.

\section{SUMMARY}

Exhibit 3 presents a summary of the strategy analysis issues discussed in this paper. Additionally, we understand that some of the curriculum and policy variables at UB will not apply to all university's academic guidelines. For example, certain programs will not, perhaps, offer enough electives to allow students the guarantee that all courses will be transferable to another degree program or concentration in the event that the new program is not ultimately approved. As we noted, the GVPP program in the school of Public Affairs provides the appropriate linkage at the UB undergraduate level, while the Master of Public Administration program offers the same benefits at the graduate level. It is essential to predict the support necessary to achieve success; including carefully developing the internal and external contacts required to meet the goals identified in our paper.

We believe our strategies for success can be applied in other university and program settings. The healthcare employment market in the greater Baltimore region provided a significant student population base from which we where able to draw for enrollment in our HSMG program. Given the statistics noted in this paper, other regional markets can be addressed to meet the education needs of the students and enhance the achievement of university program enrollment goals.

\section{Exhibit 3: Summary Of Strategy Analysis Issues}
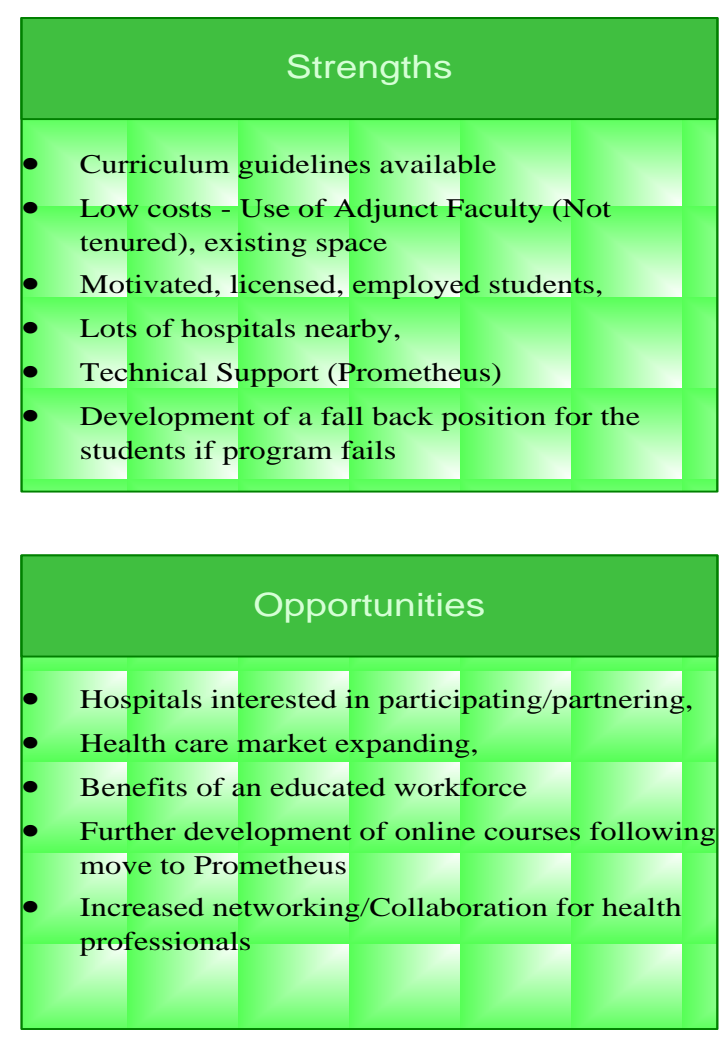
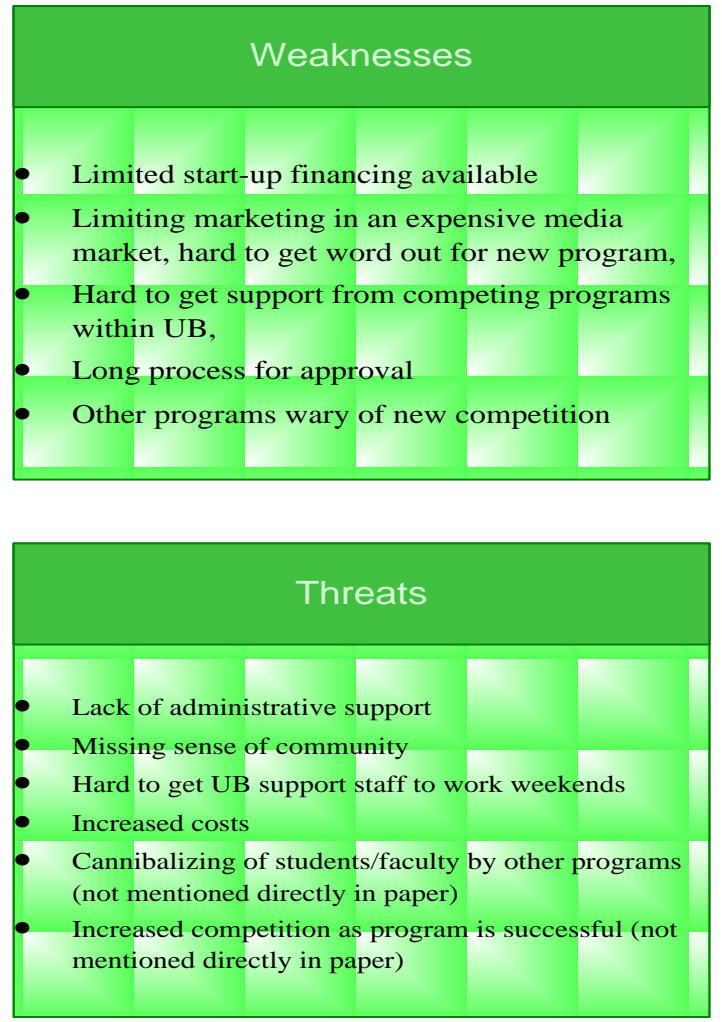


\section{REFERENCES}

1. Arnold, P. (2000) Working in the Health Field: 1996-2006. Maryland Department of Labor, Licensing and Regulation, Office of Labor Market Analysis and Information. Baltimore, MD (April).

2. Association of University Programs of Health Administration (2003). Health Services Administration Education Directory of Programs 2003-2005. Washington, DC. AUPHA

3. Barnett, B.G., Basom, M.R., Yerkes, D.M., \& Norris, C.J. (2000). Cohorts in Educational Leadership Programs: Benefits, Difficulties, and the Potential for Developing School Leaders, Educational Administration Quarterly, 36(2): 255-82.

4. US Department of Labor, Bureau of Labor Statistics (2005), Occupational Outlook Handbook 2004-2005. Washington, DC, Bureau of Labor statistics, http://stats.bls.gov/oco/ocos014.htm).

\section{NOTES}


NOTES 